\title{
Rocha com espodumênio como fundente para massas cerâmicas tradicionais
}

\section{(Spodumene rock as a flux for traditional ceramic bodies)}

\author{
S.R. Bragança ${ }^{I}$, H. C.M. Lengler ${ }^{2}$, C. P. Bergmann ${ }^{1}$ \\ ${ }^{I}$ Departamento de Materiais, Universidade Federal do Rio Grande do Sul - DEMAT/UFRGS \\ Av. Osvaldo Aranha 99/705c, Porto Alegre, RS 90035-190 \\ ${ }^{2}$ Colorminas - Colorifício e Mineração S.A. \\ saulorb@ufrgs.br
}

\begin{abstract}
Resumo
Investigou-se a atuação de uma rocha com espodumênio como fundente em massas cerâmicas, analisando-se sua reatividade com outras matérias-primas, como quartzo e caulim. Primeiramente, caracterizou-se petrograficamente o pegmatito de onde se extrai esse fundente. Posteriormente avaliou-se o comportamento de moabilidade, fundência e deformação piroplástica da rocha com espodumênio. Analisou-se então sua influência nas propriedades tecnológicas finais das peças, principalmente em relação à temperatura de queima, às fases e à microestrutura. Comparou-se a gresificação com outros fundentes comerciais como a albita e o feldspato. O espodumênio mostrou maior capacidade de reduzir a temperatura de gresificação das peças que os fundentes tradicionais, promovendo a densificação por fluxo viscoso.
\end{abstract}

Palavras-chave: cerâmica tradicional, espodumênio, fundentes, queima.

Abstract

A spodumene rock was used as a flux in ceramic bodies, analyzing its reactivity to other raw materials such as quartz and kaolin. The petrology properties of the pegmatite (parent rock) from which the flux is extracted was characterized. The grindability, fluxing strength and pyroplastic deformation of the spodumene rock were investigated. The influence on technological properties of the final pieces, mainly in relation to the firing temperature, phases formation and microstructure were also further analyzed. The firing behavior to other commercial flux such as albite and feldspar were then compared. The spodumene rock was considered an effective flux, capable of reducing the firing temperatures of the tested bodies by viscous flow.

Keywords: traditional ceramics, spodumene, fluxes, firing.

\section{INTRODUÇÃO}

A seleção de matérias-primas deve ter como critérios básicos as propriedades requeridas ao produto final e as características inerentes ao processamento cerâmico. As propriedades tecnológicas finais dos produtos cerâmicos são criticamente dependentes da composição química e mineralógica das matérias-primas empregadas [1].

As particularidades das matérias-primas de cada país exigem uma adaptação da formulação, ou até mesmo, de seu beneficiamento, a fim de oportunizar o uso de jazidas próximas às indústrias cerâmicas, minimizando assim, custos de transporte. Neste sentido, vários estudos têm sido realizados incorporando granito [2], fonolito [3, 4], além de outros feldspatóides, às massas cerâmicas. Há alguns anos, consolidou-se o uso de nefelina sienítica em cerâmicas triaxiais [5,6]. Estudos têm demonstrado também a utilização de materiais reciclados, como vidro sodo-cálcico [7-9]. Em comum, todos esses fundentes devem possuir baixo teor de ferro para não conferir à massa cerâmica uma forte tonalidade, o que comprometeria a utilização das composições na produção de produtos cerâmicos de cor clara.

Os fundentes proporcionam as primeiras fases líquidas que aparecem durante a queima. Portanto, são os principais responsáveis pelo processo de densificação, contribuindo para a diminuição da porosidade das peças, conferindolhes algumas das propriedades tecnológicas desejadas. As características que devem ser observadas na escolha de um fundente são: as fases minerais presentes, principais e secundárias, as impurezas e a granulometria $[10,11]$.

$\mathrm{Na}$ composição de uma massa de grês porcelanato, utilizam-se ainda outras matérias-primas que aumentam a fusibilidade da mesma. São geralmente fundentes enérgicos os quais são utilizados quando se tem certa dificuldade em reduzir a absorção de água na massa para valores abaixo de $1 \%$. Os materiais de natureza magnesiana, tais como o talco, são os mais usados em função de sua eficiência. Apesar das vantagens que proporcionam, a adição de fundentes enérgicos pode originar diferentes problemas, tais como a falta de estabilidade dimensional e a deformação nas peças obtidas $[12,13]$. 
Tabela I - Composição química do quartzo, caulim, albita, feldspato e rocha com espodumênio. Composição das formulações investigadas neste trabalho. Somatório dos óxidos fundentes das matérias-primas.

[Table I - Chemical composition of quartz, kaolin, abite, feldspar and spodumene rock. Compositions of the bodies. Sum of fluxing oxides in raw materials.]

\begin{tabular}{|c|c|c|c|c|c|c|c|c|c|c|}
\hline $\begin{array}{c}\text { Óxidos } \\
(\%)\end{array}$ & $\begin{array}{l}\text { Quartzo } \\
\text { (Q) }\end{array}$ & $\begin{array}{l}\text { Caulim } \\
\text { (C) }\end{array}$ & $\begin{array}{l}\text { Albita } \\
\text { (A) }\end{array}$ & $\begin{array}{l}\text { Felds- } \\
\text { pato } \\
(\mathrm{F})\end{array}$ & $\begin{array}{l}\text { Rocha } \\
\text { com } \\
\text { Espodu- } \\
\text { mênio (E) }\end{array}$ & $\begin{array}{c}50 \% \mathrm{E}+ \\
50 \% \mathrm{Q}\end{array}$ & $\begin{array}{c}50 \% \mathrm{E} \\
+ \\
50 \% \mathrm{C}\end{array}$ & $\begin{array}{c}50 \% \mathrm{C} \\
+ \\
25 \% \mathrm{Q} \\
+ \\
25 \% \mathrm{~F}\end{array}$ & $\begin{array}{c}50 \% \mathrm{C} \\
+ \\
25 \% \mathrm{Q} \\
+ \\
25 \% \mathrm{E}\end{array}$ & $\begin{array}{c}50 \% \mathrm{C} \\
+ \\
25 \% \mathrm{Q} \\
+ \\
25 \% \mathrm{~A}\end{array}$ \\
\hline $\mathrm{SiO}_{2}$ & 99,81 & 46,89 & 67,74 & 67,02 & 77,03 & 88,42 & 61,96 & 65,15 & 67,65 & 65,33 \\
\hline $\mathrm{Al}_{2} \mathrm{O}_{3}$ & 0,12 & 38,05 & 20,84 & 19,22 & 15,26 & 7,69 & 26,66 & 23,86 & 22,87 & 24,27 \\
\hline $\mathrm{Fe}_{2} \mathrm{O}_{3}$ & 0,08 & 0,46 & 0,17 & 0,19 & 0,12 & 0,10 & 0,29 & 0,30 & 0,28 & 0,29 \\
\hline $\mathrm{CaO}$ & - & 0,02 & 0,53 & 0,06 & 0,26 & 0,13 & 0,14 & 0,03 & 0,07 & 0,14 \\
\hline $\mathrm{Na}_{2} \mathrm{O}$ & 0,03 & 0,03 & 9,5 & 3,75 & 3,23 & 1,63 & 1,63 & 0,96 & 0,83 & 2,40 \\
\hline $\mathrm{K}_{2} \mathrm{O}$ & 0,06 & 1,14 & 0,62 & 9,42 & 1,21 & 0,64 & 1,18 & 2,94 & 0,88 & 0,74 \\
\hline $\mathrm{Li}_{2} \mathrm{O}$ & - & - & - & - & $2,18^{*}$ & 1,09 & 1,09 & - & 0,54 & - \\
\hline $\mathrm{TiO}_{2}$ & 0,07 & 0,03 & 0,08 & - & 0,02 & 0,05 & 0,03 & 0,03 & 0,04 & 0,05 \\
\hline $\mathrm{MgO}$ & - & - & 0,01 & - & 0,01 & 0,01 & 0,01 & 0,00 & 0,01 & 0,01 \\
\hline $\mathrm{MnO}$ & - & 0,01 & 0,01 & 0,01 & 0,06 & 0,03 & 0,04 & 0,01 & 0,02 & 0,01 \\
\hline $\mathrm{P}_{2} \mathrm{O}_{5}$ & 0,02 & 0,11 & 0,01 & - & 0,07 & 0,05 & 0,09 & 0,06 & 0,07 & 0,06 \\
\hline $\mathrm{PF}$ & 0,1 & 13,2 & 0,35 & 0,6 & 0,63 & 0,37 & 6,92 & 6,78 & 6,78 & 6,71 \\
\hline Total & 100,3 & 99,94 & 99,86 & 100,2 & 100,08 & 100,1 & 100,0 & 100,1 & 100,1 & 100,1 \\
\hline $\begin{array}{c}\Sigma: \\
\text { Alcalinos }\end{array}$ & 0,09 & 1,17 & 10,12 & 13,17 & 6,62 & 3,36 & 3,90 & 3,90 & 2,26 & 3,14 \\
\hline
\end{tabular}

* análise por absorção atômica.

Tabela II - Fases identificadas por difração de raios X em cada matéria-prima, após moagem. Listadas as fases de maior importância.

[Table II - Raw material XRD phase analysis, after milling. Major phases are shown.]

\begin{tabular}{|c|c|c|c|}
\hline \multicolumn{3}{|c|}{ Constituintes Presentes } & \multirow{2}{*}{$\begin{array}{c}\text { DRX-JCPDS. } \\
\text { Número do arquivo } \\
01-0739\end{array}$} \\
\hline Albita & Albita & $\mathrm{NaAlSi}_{3} \mathrm{O}_{8}$ & \\
\hline \multirow{4}{*}{ Feldspato } & Quartzo & $\mathrm{SiO}_{2}$ & $05-490$ \\
\hline & Quartzo & $\mathrm{SiO}_{2}$ & $05-490$ \\
\hline & Microclínio & $\mathrm{KAl} \mathrm{Si}{ }_{3} \mathrm{O}_{8}$ & $22-675$ \\
\hline & Albita & $\mathrm{NaAlSi}_{3} \mathrm{O}_{8}$ & 01-0739 \\
\hline Quartzo & Quartzo & $\mathrm{SiO}_{2}$ & $05-490$ \\
\hline Caulim & Caolinita & $\mathrm{Al}_{2} \mathrm{Si}_{2} \mathrm{O}_{5}(\mathrm{OH})_{4}$ & $14-164$ \\
\hline \multirow{5}{*}{$\begin{array}{l}\text { Rocha com } \\
\text { Espodumênio }\end{array}$} & Quartzo & $\mathrm{SiO}_{2}$ & $05-490$ \\
\hline & Muscovita & $\mathrm{KAl}_{2} \mathrm{Si}_{3} \mathrm{AlO}_{10}(\mathrm{OH})_{2}$ & 03-0849 \\
\hline & Espodumênio & $\mathrm{LiAlSi}_{2} \mathrm{O}_{6}$ & $33-0786$ \\
\hline & Quartzo & $\mathrm{SiO}_{2}$ & $05-490$ \\
\hline & Albita & $\mathrm{NaAlSi}_{3} \mathrm{O}_{8}$ & 01-0739 \\
\hline Quartzo & Quartzo & $\mathrm{SiO}_{2}$ & $05-490$ \\
\hline
\end{tabular}

Recentemente, tem-se destacado a utilização de matériasprimas que contenham espodumênio em sua composição. Devido ao alto custo da forma sintética, como carbonato de lítio, tem-se utilizado, principalmente, a forma mineral, em maior ou menor concentração, a partir de rochas como pegmatitos graníticos [6]. 
A utilização de espodumênio na composição de porcelanatos, substituindo parcialmente o feldspato sódico, com considerável ganho de redução na temperatura de queima, foi demonstrada [8]. Porcelanas triaxias foram analisadas, empregando-se, primeiramente, carbonato de lítio e, num segundo momento, rochas contendo espodumênio. Os autores conseguiram uma redução de $100-120{ }^{\circ} \mathrm{C}$ na temperatura de gresificação e concluíram que os teores de $\mathrm{Li}_{2} \mathrm{O}$ não devem exceder $\sim 1,5 \%$, para não se perder em densificação das peças [14]. $\mathrm{O}$ uso de espodumênio, com aporte de 1 a 1,6\% de $\mathrm{Li}_{2} \mathrm{O}$ à massa, mostrou-se benéfico para produção de porcelanas de alta alumina, com ganho de densificação, resistência mecânica e diminuição da temperatura de queima [15].

No presente trabalho, propôs-se estudar a utilização de uma rocha com características fundentes, a qual apresenta o mineral espodumênio. Realizaram-se diversos testes em relação à reatividade com quartzo, caulim e misturas dessas matérias-primas, comparando-se esse fundente com outros comerciais, como feldspato e albita. Finalizou-se com a caracterização tecnológica, estudo das fases formadas e análise microestrutural.

\section{MATERIAIS E MÉTODOS}

A composição das matérias-primas por fluorescência de raios X (Shimadzu XRF-1800) e por absorção atômica (para o óxido de lítio) é mostrada na Tabela I. Nesta tabela constam ainda as quatro formulações estudadas $(50 \%$ rocha com espodumênio $+50 \%$ quartzo; $50 \%$ rocha com espodumênio $+50 \%$ caulim; $50 \%$ rocha com espodumênio $+50 \%$ talco; $25 \%$ rocha com espodumênio $+25 \%$ quartzo + $50 \%$ caulim) com as composições inferidas de acordo com o percentual de cada parte e o somatório dos óxidos fundentes (alcalinos $+\mathrm{Fe}_{2} \mathrm{O}_{3}$; alcalinos terrosos). As fases cristalinas determinadas por difração de raios X (Phillips X'pert MPD) são apresentadas na Tabela II.

O caulim, proveniente de Pântano Grande, RS, produzido pela empresa Caulim Olivério Ltda., é bastante comercializado na região sul do Brasil. A albita foi fornecida pela empresa Marc Mineração, Ponta Grossa, PR, apresentando grande concentração desse mineral na rocha beneficiada. O feldspato é proveniente da concentração de rocha granítica, beneficiada pela empresa Mineração Sartor, Pedras Grandes, SC. O quartzo foi fornecido pela empresa Sibelco S.A. e é bastante consumido pelas indústrias cerâmicas brasileiras. A rocha com espodumênio foi fornecida pela Colorminas - Colorifício e Mineração S.A., sendo um sub-produto da mineração de pegmatitos de Minas Gerais. Não foi ainda viabilizado nenhum método para concentrar o espodumênio, encontrando-se no mercado, portanto, como uma rocha (rejeito após a retirada de minerais de tântalo) com albita, quartzo e espodumênio. Por esse motivo, é chamado de "rocha com espodumênio".

As massas granuladas foram compactadas, utilizando-se uma prensa hidráulica de simples efeito com estampo metálico, com as dimensões $20 \times 60 \mathrm{~mm}^{2}$, com altura de $\sim 7 \mathrm{~mm}$, com pressão de compactação de $\sim 20 \mathrm{MPa}$. O valor da densidade a verde foi mantido em torno de $1,7 \mathrm{~g} / \mathrm{cm}^{3}$.

Os corpos cerâmicos foram secos em temperatura ambiente por $24 \mathrm{~h}$ e após este período em estufa a $110{ }^{\circ} \mathrm{C}$ por mais $24 \mathrm{~h}$. A queima foi em fornos elétricos tipo mufla, variando-se a temperatura entre $1140{ }^{\circ} \mathrm{C}$ e $1200{ }^{\circ} \mathrm{C}$, com $300 \mathrm{~K} / \mathrm{min}$ e patamar de $30 \mathrm{~min}$ na temperatura máxima de queima. Foram determinadas as propriedades de gresificação dos corpos cerâmicos e fases formadas após a queima. Os resultados obtidos foram associados com sua microestrutura e formulação. Em especial, a porosidade foi avaliada quanto sua distribuição, morfologia e tamanho e sua influência na definição da microestrutura final, relacionando-se com propriedades dos corpos cerâmicos investigados. A microestrutura foi observada em microscópio eletrônico de varredura Philips XL-20. As amostras foram preparadas por polimento (com lixas em grana crescente, finalizandose com suspensão de alumina em água), seguido ou não de ataque ácido (HF 20\%, em diferentes tempos) para remoção da fase vítrea.

Para a análise petrográfica as lâminas foram extraídas da amostra de rocha, cortadas com disco diamantado, posteriormente, polidas (em uma politriz com lixas em grana crescente e finalizando-se com suspensão de alumina em água) até adquirirem uma espessura de aproximadamente 30 $\mu \mathrm{m}$ e coladas em uma lâmina de vidro. As análises foram efetuadas em microscópio petrográfico binocular Leitz HMP01. Este microscópio permitiu a utilização de técnicas de análises chamadas "luz natural" e "luz polarizada".

As matérias-primas foram moídas a seco, tentando evitar ao máximo a contaminação dos agentes de moagem e similarizando, tanto quanto possível, os processos industriais utilizados pelas empresas fabricantes de revestimentos cerâmicos. Foi empregado um moinho de bolas com corpos moedores de alta alumina $\left(>92 \% \mathrm{de}_{2} \mathrm{O}_{3}\right)$, de três diferentes diâmetros: 20,16 e $12 \mathrm{~mm}$. Os tempos de moagem para cada fundente foram 2, 4, 9, 14, 24, 30, $60 \mathrm{e}$ $90 \mathrm{~min}$. Para as formulações, utilizou-se posterior moagem de 15 min, mostrando boa mistura das matérias-primas em análise em lupa.

O índice de piroplasticidade foi medido de acordo com o modelo apresentado em [16], calculado pela equação A, onde $I P$ é o índice de piroplasticidade $\left(\mathrm{cm}^{-1}\right), h$ é a espessura do corpo $(\mathrm{cm}), S$ é a flecha de deformação (medida pela deflexão do corpo de prova), e $L$ é a distância entre os apoios. As barras retangulares utilizadas no ensaio foram de $200 \times 60 \times 7 \mathrm{~mm}^{3}$, com distância entre apoios de $110 \mathrm{~mm}$.

$$
\mathrm{IP}=4 \mathrm{~h}^{2} \mathrm{~S} / 3 \mathrm{~L}^{4}
$$

A análise da distribuição do tamanho de partículas das amostras de matérias-primas foi feita por difração laser (Cilas 1180). A área superficial específica foi analisada no equipamento Quantachrome (Nova 1000). Os cones de fusão foram feitos com compactação manual e queima a $1280{ }^{\circ} \mathrm{C}$, com taxa de aquecimento $5 \mathrm{~K} / \mathrm{min}$ e 6 min de patamar na temperatura máxima. 


\section{RESULTADOS E DISCUSSÃO}

Análise petrográfica do pegmatito que contém a rocha com espodumênio

A rocha mãe que contém o espodumênio ocorre megascopicamente na forma de um grande pegmatito. Tanto macro como microscopicamente, verifica-se que a mineralogia essencial é composta por plagioclásio, ortoclásio e quartzo. O plagioclásio é subédrico com dimensão média de $0,5 \mathrm{~mm}$. Sua alteração é incipiente e mostra contatos irregulares. É classificado pela técnica de Michel-Lévy como oligoclásio $(A n=18)$. O ortoclásio tem dimensões maiores que $2 \mathrm{~mm}$ de forma euédrica. Apresenta poucas inclusões de minerais máficos. O quartzo tem dimensão média de $0,1 \mathrm{~mm}$ de hábito granular e forma anédrica. Não é disposto de maneira homogênea na rocha, muitas vezes, formando agregados intersticiais e fazendo parte de uma matriz também composta por feldspato alcalino e piroxênio.

A mineralogia varietal é composta por espodumênio e lepidolita. A lepidolita, de dimensão média de 0,4 mm, apresenta forma subédrica e hábito lamelar, enquanto o espodumênio, de dimensão média $2 \mathrm{~mm}$, tem forma geral subédrica e contatos irregulares. A Tabela III apresenta uma estimativa visual da composição mineralógica dessa rocha. Sua classificação petrográfica QAPF é de lepidolita espodumênio monzogranito.

Tabela III - Composição mineralógica por estimativa visual da rocha mãe que contém o espodumênio.

[Table III - Mineralogical composition, estimated by visual analysis of the spodumene parent rock.]

\begin{tabular}{cc}
\hline Mineral & \% volume \\
\hline plagioclásio & 25 \\
ortoclásio & 15 \\
quartzo & 30 \\
espodumênio & 15 \\
lepidolita & 15 \\
\hline
\end{tabular}

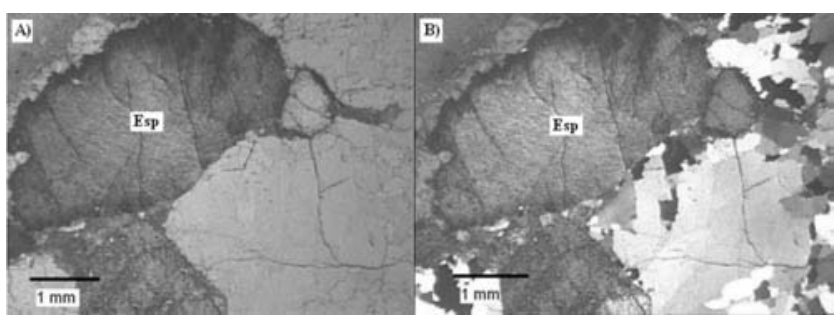

Figura 1: Fotomicrografia em lâmina petrográfica do pegmatito. A) sob luz natural. B) sob luz polarizada.

[Figure 1: Optical micrograph of the pegmatite. A) natural light. B) polarized light.]

As Figs. 1A e 1B apresentam as fotografias das lâminas petrográficas da amostra do pegmatito, sob luz natural e luz polarizada, respectivamente, onde se destaca um grão de espodumênio.
A retirada dos minerais de tântalo leva consigo parte dos minerais da rocha mãe (pegmatito). $\mathrm{O}$ rejeito utilizado neste trabalho, denominado rocha com espodumênio, apresenta as seguintes fases, detectadas por difração de raios X: espodumênio, albita, quartzo e um alumino-silicato (Fig. 2). A diferença em relação à composição feita por análise petrográfica (Tabela II) deve-se ao processo de beneficiamento do pegmatito, de modo que fases como a lepidolita ficam em teores menores que o mínimo para a detecção por difratometria. Ao mesmo tempo, podem ocorrer alterações devido à britagem/cominuição da rocha, as quais interferem na detecção das fases.

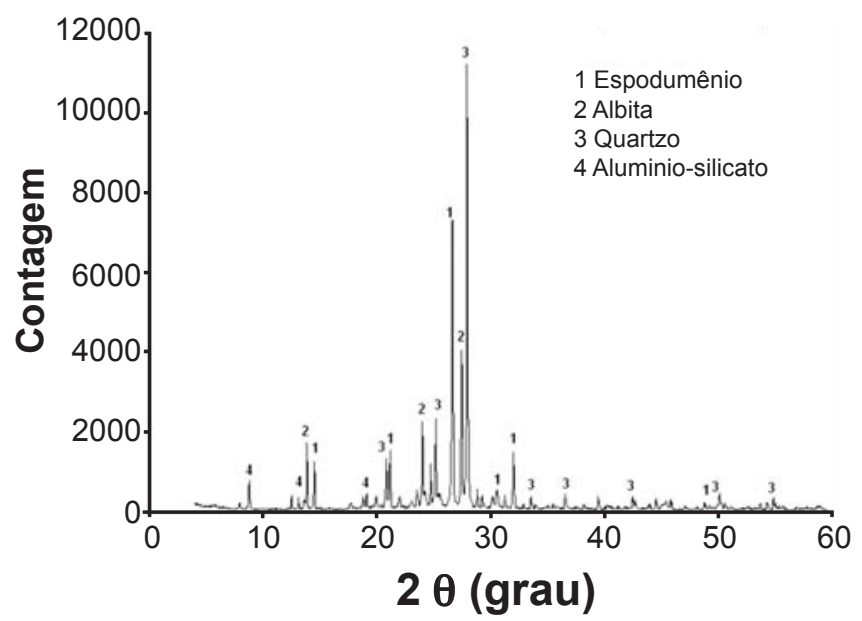

Figura 2: Difratograma de raios $\mathrm{X}$ da rocha com espodumênio. [Figure 2: XRD pattern of spodumene rock.]

\section{Avaliação da moabilidade da rocha com espodumênio}

A rocha com espodumênio foi submetida a uma seqüência de moagem com tempos pré-determinados, a fim de se verificar a evolução da distribuição granulométrica e identificar a variabilidade das curvas de distribuição granulométricas, visto que cada matéria-prima é distinta nas suas propriedades mineralógicas. A Fig. 3A apresenta a variação do tamanho médio das partículas em função do tempo de moagem, a partir da amostra britada industrialmente. A curva de distribuição granulométrica é mostrada na Fig. 3B, na qual se apresenta a distribuição de tamanhos de partícula para os tempos de moagem de 0 a $34 \mathrm{~min}$.

A rocha com espodumênio apresentou boa friabilidade, como mostra a Fig. 3A, com significativa redução do diâmetro médio de partícula. No entanto, a moabilidade dos minerais de maior dureza como quartzo e o espodumênio é mais difícil, de modo que ainda persistem como fração mais grosseira (Fig. 3B). Na Fig. 4 observa-se a mudança de textura das partículas, comparando-se seu aspecto antes (Fig. 4A) e após a moagem (Fig. 4B). Partículas de espodumênio apresentam morfologia nitidamente irregular, com arestas bem definidas, já que cristalizam no sistema monoclínico, cujo aspecto é similar ao grão em destaque na Fig. 4B. 
(a)

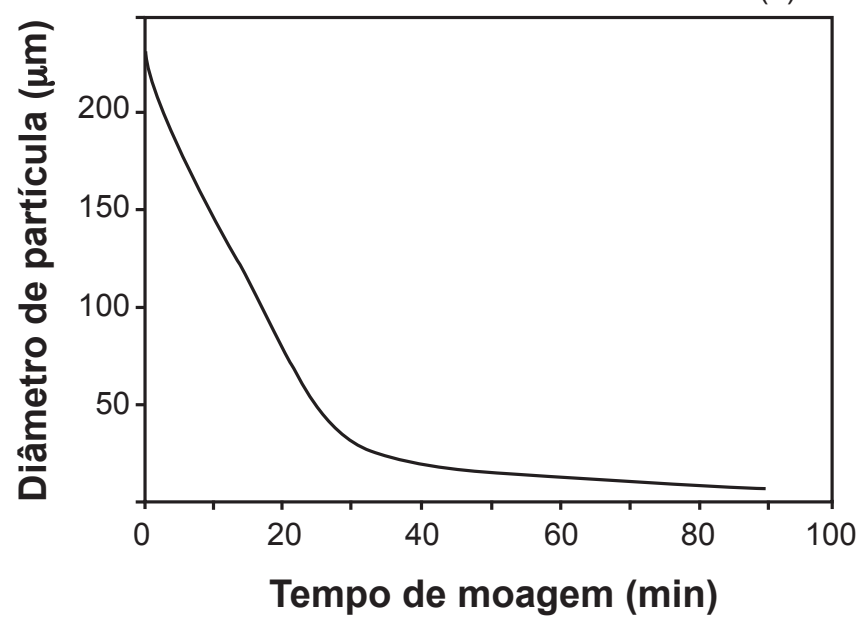

(b)

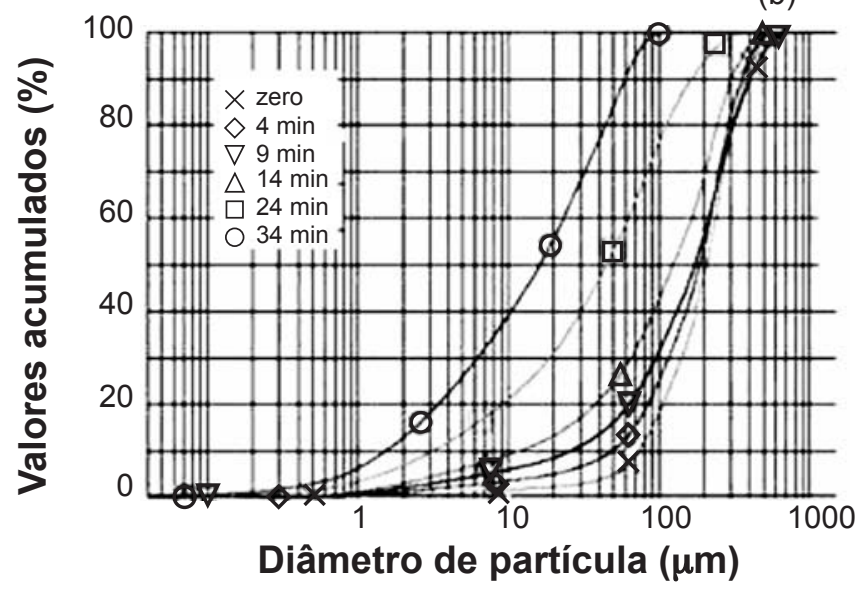

Figura 3: Rocha com espodumênio. a) Variação do diâmetro médio de partícula com o tempo de moagem. b) Distribuição do tamanho de partículas para diferentes tempos de moagem (curva zero, antes da moagem).

[Figure 3: Spodumene rock. a) Mean particle diameter as a function of milling time. b) Sum frequency of the size distribution for different milling time (zero curve, before milling).]
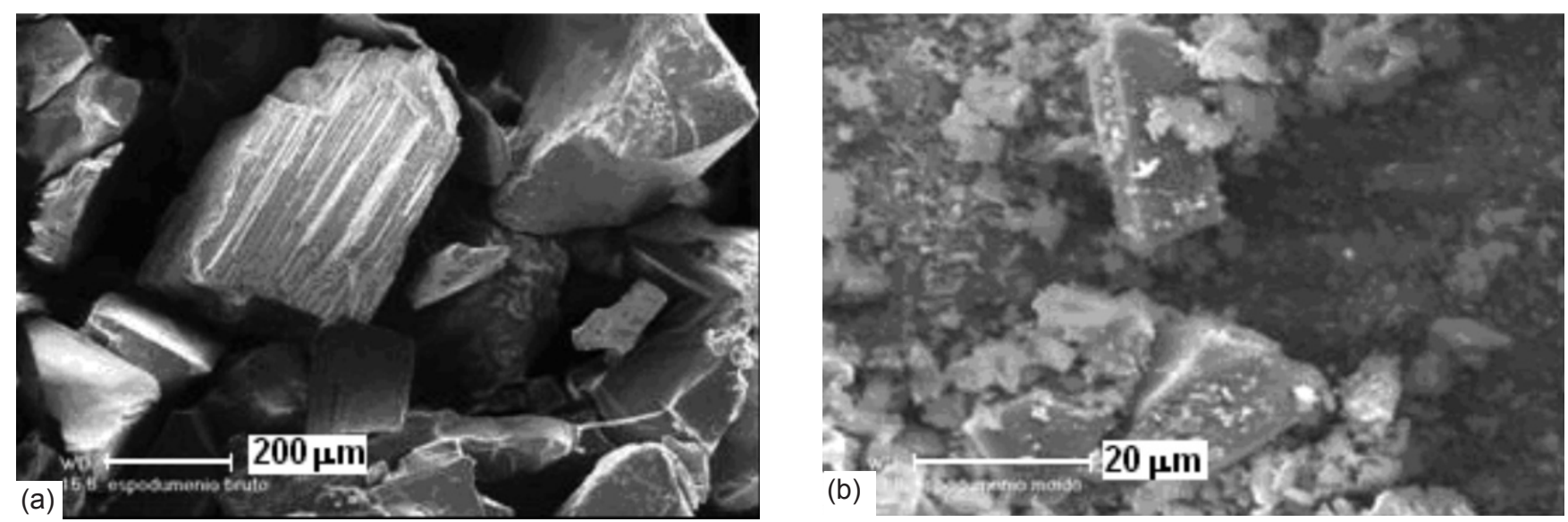

Figura 4: Micrografias obtidas por microscopia eletrônica de varredura mostrando a morfologia dos grãos da rocha com espodumênio. a) antes da moagem; b) após moagem (34 min).

[Figure 4: SEM micrographs showing spodumene rock grains morphology. a) before milling. b) after milling (34 min).]

Avaliação da piroplasticidade e dilatação térmica da rocha com espodumênio

O ensaio de piroplasticidade permite prever o comportamento da fase vítrea ou de sua viscosidade em massas cerâmicas em função da temperatura de queima [17]. No ensaio apresentado na Fig. 5 pode se verificar que a temperatura de formação da fase líquida (em quantidade significativa), na qual a viscosidade é baixa suficiente para permitir a deformação da peça, é de cerca de $1125^{\circ} \mathrm{C}$, atingindo o máximo de deformação em $1200{ }^{\circ} \mathrm{C}$. Isto significa que a composição da rocha com espodumênio apresenta eutéticos de baixa temperatura, provavelmente, devido à reação dos óxidos fundentes com a sílica e a alumina, conforme a composição apresentada na Tabela I. Esses eutéticos determinam uma baixa viscosidade da fase vítrea, o que explica o comportamento mostrado pelo índice de piroplasticidade.
A Fig. 6 apresenta a curva da dilatação térmica do fundente investigado, considerando-se o comportamento dilatométrico durante o aquecimento e o resfriamento. A $1000^{\circ} \mathrm{C}$ inicia-se a sinterização. A $\sim 570^{\circ} \mathrm{C}$ ocorre a inversão cristalográfica do quartzo, no aquecimento e no resfriamento. $\mathrm{O}$ coeficiente de expansão térmica linear calculado em função da inclinação média da curva de resfriamento, entre $25^{\circ} \mathrm{C}$ e $1000{ }^{\circ} \mathrm{C}$, foi $10 \cdot 10^{-6}$. $\mathrm{K}^{-1}$. Este resultado é próximo de outros fundentes comerciais [4], portanto, a influência da fase espodumênio- $\beta\left(\alpha=1.10^{-6} \cdot \mathrm{K}^{-1}\right)$, formada logo acima de $1000{ }^{\circ} \mathrm{C}$, não é significativa, ou, alternativamente, fica minimizada em função da presença do quartzo.

A análise dilatométrica e o ensaio de deformação piroplástica demonstraram que a rocha com espodumênio começa a sinterizar logo acima de $1000{ }^{\circ} \mathrm{C}$. Em função dessas análises, destaca-se que ela apresenta bom potencial como fundente auxiliar à gresificação cerâmica. 


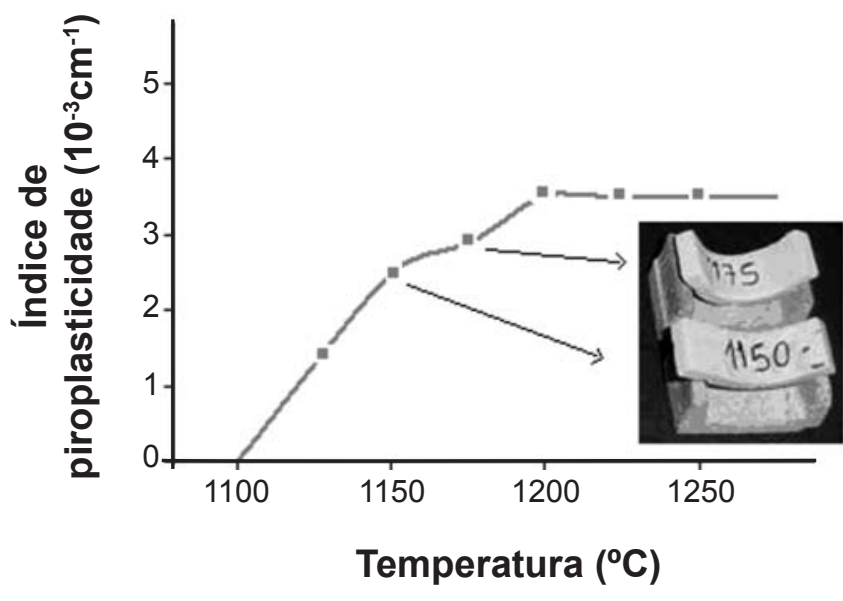

Figura 5: Índice de piroplasticidade em função da temperatura de queima e ilustração da deformação sobre queima das peças, para a composição com $100 \%$ de rocha com espodumênio.

[Figure 5: Pyroplastic deformation as a function of firing temperature. Photograph of deformed pieces. Spodumene rock.]

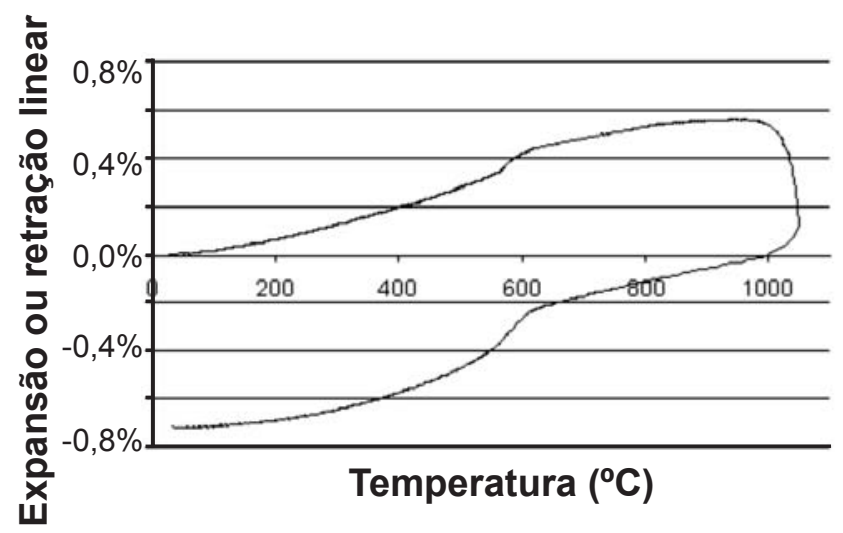

Figura 6: Expansão térmica linear da rocha com espodumênio. [Figure 6: Linear thermal expansion of the spodumene rock.]

Avaliação da reatividade da rocha com espodumênio com o quartzo

Na formulação de 50\% rocha com espodumênio + 50\% de quartzo, nota-se que o fechamento da porosidade ocorre em temperaturas significativamente baixas, fazendo com que o corpo cerâmico praticamente gresifique para uma temperatura de queima de $1200{ }^{\circ} \mathrm{C}$ (Fig. 7).

A Fig. 8A mostra que a fase vítrea cobre toda a microestrutura e mesmo após o polimento, na preparação das amostras para análise no microscópio eletrônico de varredura, não se nota porosidade aberta, com exceção de alguma trinca ocasionada pela diferença de expansão térmica entre o quartzo e a fase vítrea. Em determinados locais, a viscosidade é suficientemente baixa para propiciar o crescimento da porosidade fechada. Estas áreas favorecem também a deformação piroplástica [18].

$\mathrm{Na}$ Fig. 8B observa-se a presença significativa de quartzo e uma baixa dissolução do mesmo perante a fase vítrea, já que os cristais estão com as arestas muito pouco

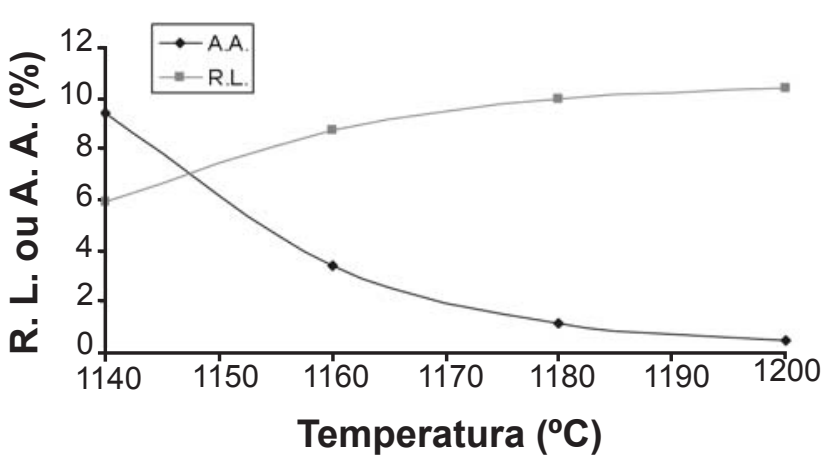

Figura 7: Retração linear e absorção de água em função da temperatura de queima. $50 \%$ quartzo $+50 \%$ rocha com espodumênio.

[Figure 7: Linear shrinkage and water absorption as a function of firing temperature. $50 \%$ quartz $+50 \%$ spodumene rock body.]
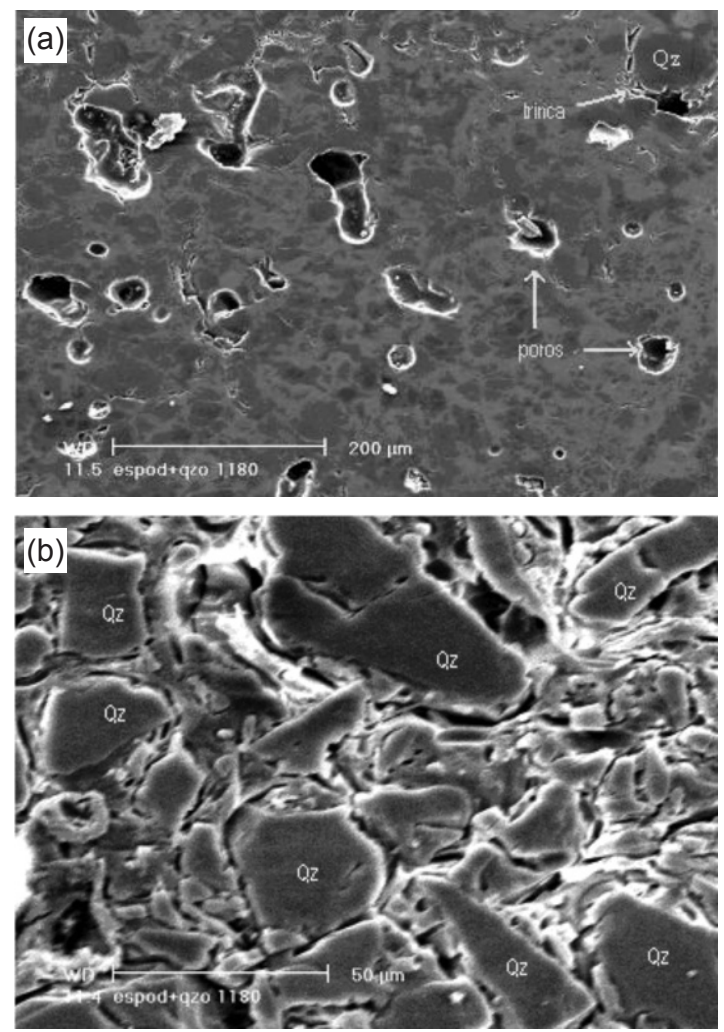

Figura 8: Micrografias do corpo cerâmico formulado com espodumênio e quartzo, queimado a $1180{ }^{\circ} \mathrm{C}$. a) sem ataque; b) ataque químico (HF 20\%, 10 s).

[Figure 8: SEM micrographs of 50\% spodumene rock $+50 \%$ quartz, body fired at $1180^{\circ} \mathrm{C}$. a) no chemical etching; b) chemical etching (HF 20\%, $10 \mathrm{~s})$.]

arredondadas. Assim, a gresificação é uma consequência direta da fundência da rocha com espodumênio, já observada nas Figs. 5 e 6, com pouca ou desprezível influência do quartzo.

A Fig. 9 mostra que os corpos cerâmicos queimados a $1140{ }^{\circ} \mathrm{C}$ apresentam duas fases cristalinas, quartzo e espodumênio, desaparecendo a albita (Fig. 2). Quando os corpos cerâmicos da mesma formulação são queimados à 


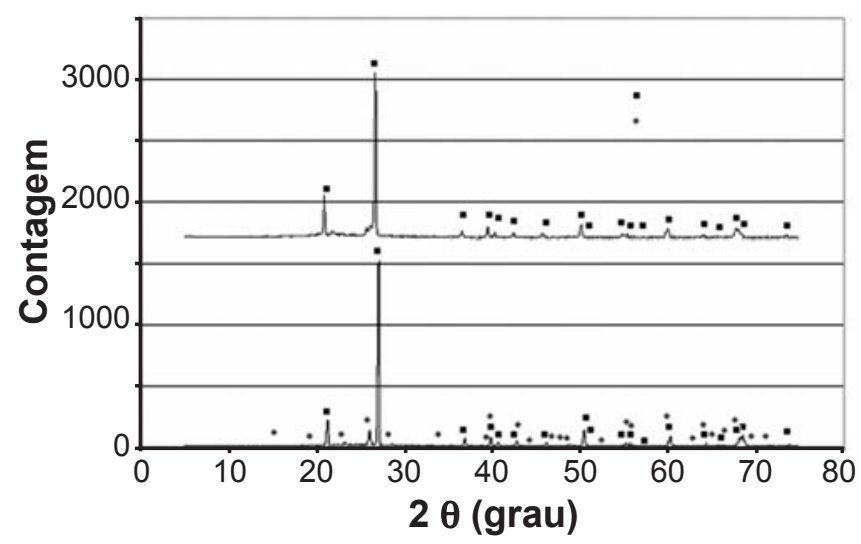

Figura 9: Difratogramas de raios $\mathrm{X}$ comparativos dos corpos cerâmicos, formulados com quartzo e espodumênio, para as temperaturas de $1140{ }^{\circ} \mathrm{C}$ e $1200{ }^{\circ} \mathrm{C}$.

[Figure 9: XRD patterns for spodumene rock + quartz composition, fired at $1140{ }^{\circ} \mathrm{C}$ and $1200{ }^{\circ} \mathrm{C}$.]

temperatura de $1200{ }^{\circ} \mathrm{C}$, não consta mais a fase cristalina espodumênio no difratograma correspondente. Face a isso, pode-se afirmar que em $1200^{\circ} \mathrm{C}$ todo o espodumênio reagiu, formando a fase vítrea, que passa a co-existir com o quartzo remanescente. Essa análise confirma o que se observou na análise microestrutural. Salienta-se também que não ocorre a formação de mulita, provavelmente pelo baixo teor de alumina $\left(7,68 \%\right.$ de $\mathrm{Al}_{2} \mathrm{O}_{3}$ da composição total, Tabela I). A formação de mulita também não é esperada pela análise no diagrama $\mathrm{Li}_{2} \mathrm{O}-\mathrm{SiO}_{2}-\mathrm{Al}_{2} \mathrm{O}_{3}$, o qual indica a formação de alumino-silicato de lítio, para a condição de equilíbrio [19].

Avaliação da reatividade da rocha com espodumênio com o caulim

A introdução do caulim, em substituição ao quartzo na formulação investigada anteriormente, fornece um constituinte formador de fase vítrea, a partir do efeito da temperatura sobre os argilominerais do caulim, portanto, favorecendo a sinterização por fase vítrea. A cerca de $900{ }^{\circ} \mathrm{C}$,

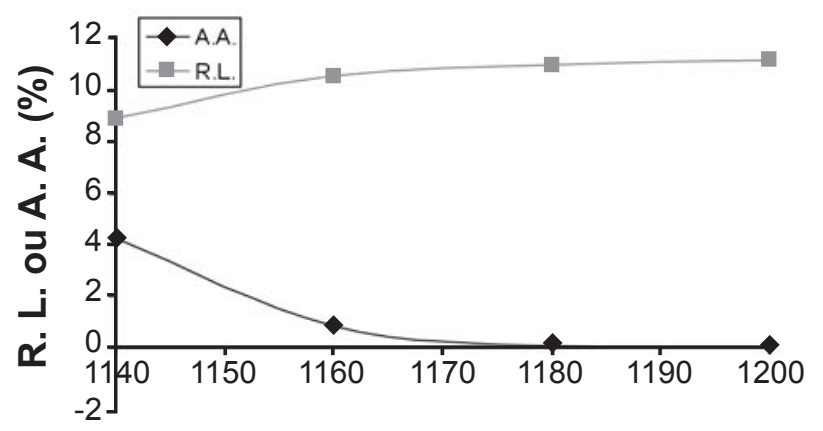

\section{Temperatura $\left({ }^{\circ} \mathrm{C}\right)$}

Figura 10: Retração linear e absorção de água em função da temperatura de queima. $50 \%$ caulim $+50 \%$ rocha com espodumênio. [Figure 10: Linear shrinkage and water absorption as a function of firing temperature. $50 \%$ kaolin $+50 \%$ spodumene rock body.]
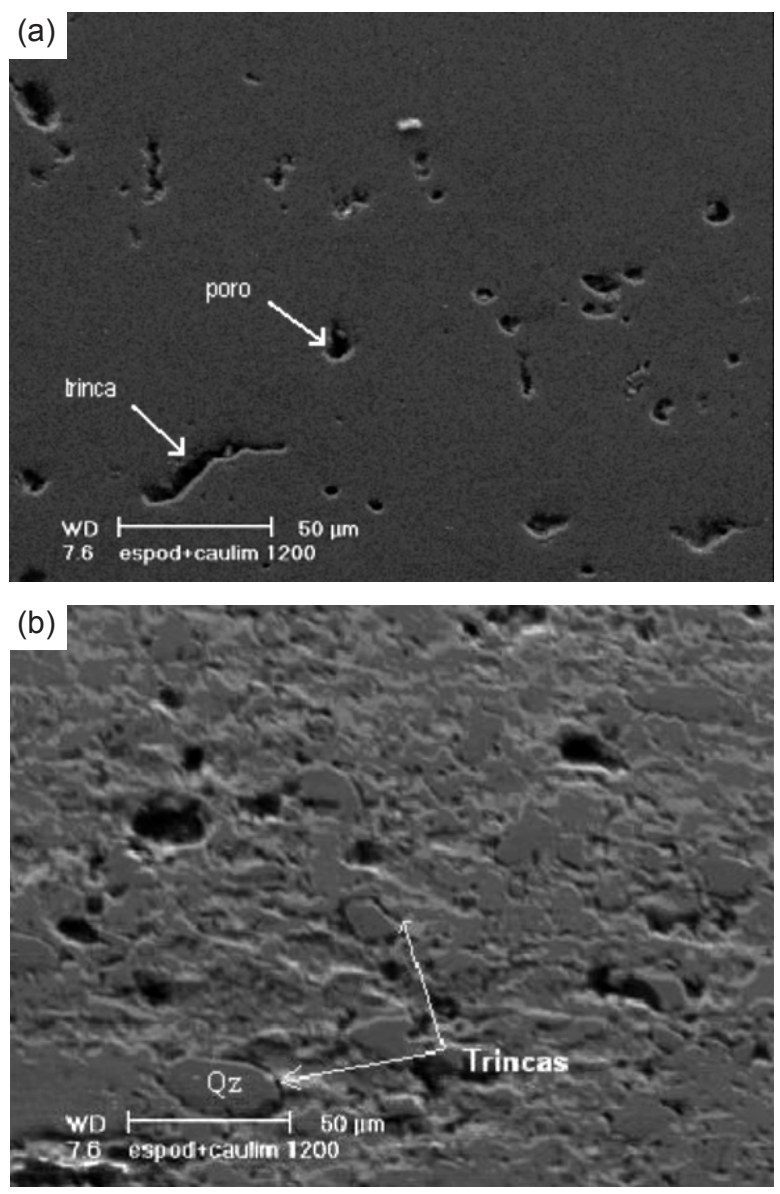

Figura 11: Micrografia do corpo cerâmico formulado com espodumênio e caulim, queimado a $1200{ }^{\circ} \mathrm{C}$. a) sem ataque; b) ataque químico (HF 20\%, $10 \mathrm{~s}$ ).

Figure 11: SEM micrographs of spodumene rock + kaolin body fired at $1200^{\circ} \mathrm{C}$. a) No chemical etching. b) Chemical etching (HF $20 \%, 10 \mathrm{~s}$ ).

a decomposição da metacaolinita libera a sílica amorfa, fase muito mais reativa que a sílica cristalina (quartzo) [5]. Este fenômeno fica claro ao se comparar a Fig. 7 com a 10. Esta última apresentou o nível de gresificação daquela em uma menor temperatura de queima - uma redução de cerca de $35^{\circ} \mathrm{C}$.

Na Fig. 11a nota-se a formação de porosidade de menor dimensão, em relação à análise da reatividade com o quartzo (Fig. 8A). A peça com caulim gresificou em menor temperatura, cerca de $1170{ }^{\circ} \mathrm{C}$. Na temperatura de queima de $1200{ }^{\circ} \mathrm{C}$ a tensão superficial da fase vítrea não permite tanta expansão da porosidade, quanto na formulação com quartzo. Isto pode ser explicado por uma provável maior dissolução do quartzo, o qual ocorre em granulometria fina no caulim, e, principalmente, pela presença de maiores teores de alumina, advinda do caulim. O quartzo se apresenta arredondado e em menor granulometria, como pode ser visto na Fig. 11b.

As trincas ressaltadas na Fig. 11b são consequência da presença de quartzo, cuja diferença de expansão térmica, em relação à fase vítrea, cria tensões capazes de trincar a matriz vítrea [20]. 


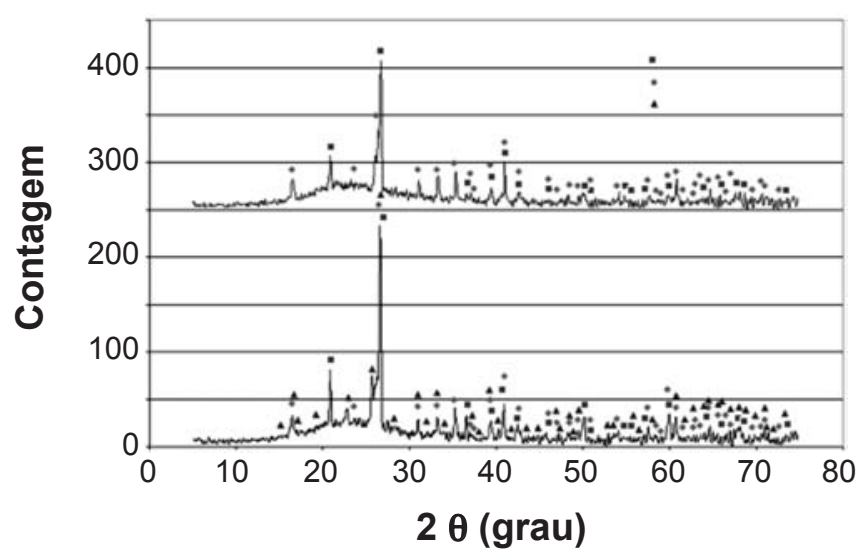

Figura 12: Difratogramas de raios $\mathrm{X}$ comparativos dos corpos cerâmicos, formulados com caulim e espodumênio, para as temperaturas de $1140{ }^{\circ} \mathrm{C}$ e $1200{ }^{\circ} \mathrm{C}$.

[Figure 12: XRD patterns for spodumene rock + kaolin composition, fired at $1140{ }^{\circ} \mathrm{C}$ and $1200{ }^{\circ} \mathrm{C}$.]

A Fig. 12 mostra que no difratograma, após $1200{ }^{\circ} \mathrm{C}$, todo o espodumênio já reagiu, restando o quartzo e mulita como fases cristalinas. Os maiores teores de alumina nessa formulação possibilitam a cristalização da mulita, como mostra a Fig. 12, o que não ocorreu na formulação de quartzo (Fig. 9).

\section{Comparação com os fundentes feldspato e albita}

A fim de se melhor avaliar a rocha com espodumênio realizou-se testes comparativos com fundentes comercias como a albita e o feldspato, utilizados na fabricação de pavimentos. Após a moagem, a área superficial BET foi 2,46 $\mathrm{g} / \mathrm{m}^{2}, 2,55 \mathrm{~g} / \mathrm{m}^{2}$ e $2,81 \mathrm{~g} / \mathrm{m}^{2}$ para o espodumênio, feldspato e albita, respectivamente. Face a isso, não se espera influência da pequena diferença de granulometria entre eles nos resultados.

A Fig. 13 mostra os cones de fusão das composições com $100 \%$ de cada fundente, comparando-se com o tamanho original do cone. Por esse ensaio fica claro a maior fundência da rocha com espodumênio.

Em termos de gresificação a rocha com espodumênio mostrou ser mais efetiva em relação aos fundentes albita e feldspato, Fig. 14. Deste modo espera-se que a utilização da rocha com espodumênio em uma formulação comercial, em substituição parcial ou total à albita ou ao feldspato,

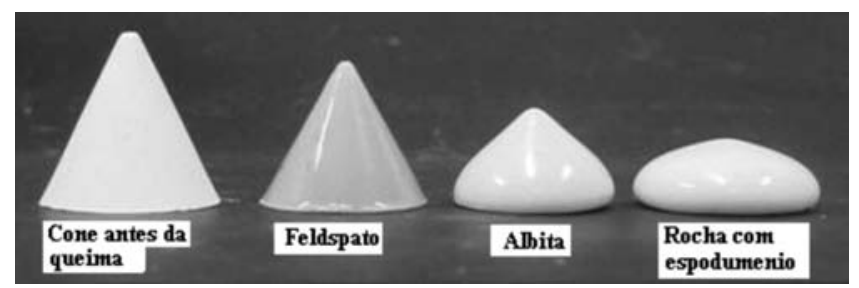

Figura 13: Cones de fusão das composições $100 \%$ feldspato, $100 \%$ de albita e $100 \%$ de rocha com espodumênio.

[Figure 13: Fusion cone test for compositions of 100\% flux. Feldspar, albite, and spodumene rock.]

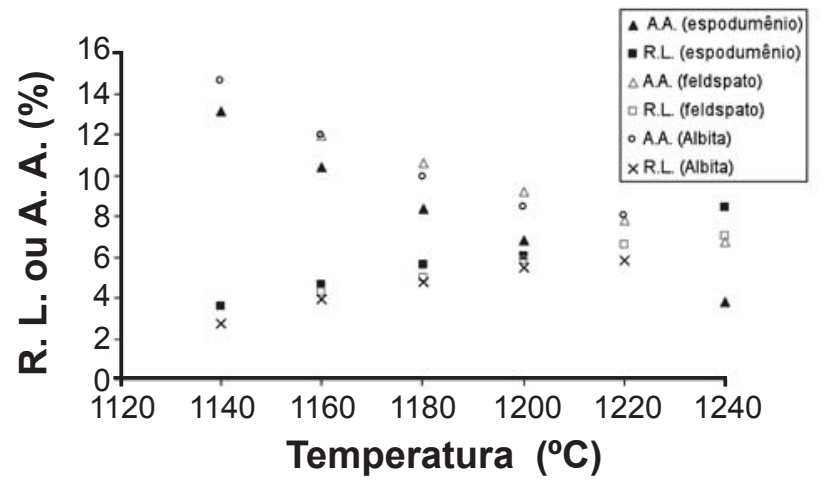

Figura 14: Retração linear e absorção de água em função da temperatura de queima. $50 \%$ caulim $+25 \%$ quartzo $+25 \%$ fundente (rocha com espodumênio ou albita ou feldspato).

[Figure 14: Linear shrinkage and water absorption as a function of firing temperature. $50 \%$ kaolin $+25 \%$ quartz $+25 \%$ flux (spodumene rock or albite or feldspar.]

deva contribuir à redução da temperatura de queima, com potencial ganho em economia energética.

As fases presentes com a rocha com espodumênio na queima com o quartzo e o caulim foram a mulita e o quartzo (Fig. 15), ou seja, as mesmas fases de produtos que utilizam outros fundentes.

É interessante notar que a composição com a rocha espodumênio apresentou maior capacidade de fundência mesmo com menor quantidade de óxidos alcalinos, em relação ao feldspato e à albita. Na Tabela I observa-se que os teores de alcalinos terrosos e óxido de ferro são bastante próximos para as formulações dos fundentes com quartzo e caulim, de modo que não se espera que eles venham a diferenciar o comportamento dos fundentes. Assim, a fundência deve ser uma consequência direta da concentração de óxidos alcalinos. Neste quesito, as composições apresentam 3,90\%, $3,14 \%$ e $2,26 \%$ para as formulações com feldspato, com albita e com a rocha com espodumênio, respectivamente.

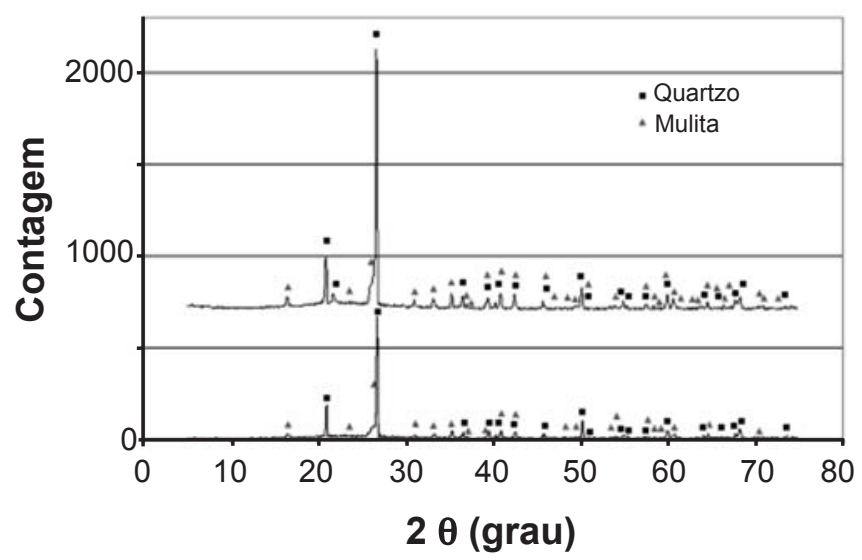

Figura 15: Difratogramas de raios $\mathrm{X}$ comparativos dos corpos cerâmicos, formulados com $50 \%$ de caulim, $25 \%$ de quartzo e $25 \%$ de rocha com espodumênio, para as temperaturas de $1140{ }^{\circ} \mathrm{C}$ e $1200{ }^{\circ} \mathrm{C}$.

[Figure 15: XRD patterns for 50\% kaolin $+25 \%$ quartz $+25 \%$ spodumene rock, body fired at $1140{ }^{\circ} \mathrm{C}$ and $1200{ }^{\circ} \mathrm{C}$.] 
Portanto, mesmo uma quantidade relativamente pequena de óxido de lítio na formulação final, cerca de $0,51 \%$, é suficiente para promover uma maior densificação das peças.

A maior capacidade de fundência do óxido de lítio é explicada pela formação de fase vítrea em menor temperatura, bem como a redução da viscosidade da mesma, como é esperado em decorrência da presença de óxidos alcalinos em vidros silicosos [21]. O pequeno íon de lítio apresenta maior coeficiente de difusão, em função de seu menor raio iônico em relação ao $\mathrm{Na}^{+}$e ao $\mathrm{K}^{+}$, modificando as propriedades da fase vítrea, de modo a acelerar a densificação por fluxo viscoso. É bem conhecido que os íons alcalinos apresentam os maiores coeficientes de difusão em silicatos líquidos [22].

\section{CONCLUSÕES}

A rocha com espodumênio investigada apresentou bom potencial como fundente para massas cerâmicas, promovendo significativa vitrificação já a partir de $1000^{\circ} \mathrm{C}$. A reatividade com o quartzo foi considerada baixa, sendo, no entanto, mais elevada com o caulim, cuja formulação apresentou gresificação em $1170{ }^{\circ} \mathrm{C}$. Comparando-se com os fundentes feldspato e albita, em uma formulação com quartzo e caulim, a rocha com espodumênio apresentou maior fundência, mesmo com sua formulação contento menor quantidade total de óxidos alcalinos. Isto confirma a importância da presença do óxido de lítio em fundentes cerâmicos, cujo pequeno íon facilita a densificação por fluxo viscoso.

\section{AGRADECIMENTOS}

Ao Departamento de Petrologia do Instituto de Geociências da UFRGS e ao CNPq pelo apoio financeiro.

\section{REFERÊNCIAS}

[1] E. Sanchez, M. J. Orts, J. García-Tem, V. Cantavella, Ceram. Ind. 6 (2001) 15-22.

[2] M. Ravagli, C. Fiori, Ceram. Inf. 330 (1993) 538.

[3] L. F. Sheibe, Geologia e Petrologia do Distrito Alcalino de Lages, SC, Tese de Doutorado, USP, S. Paulo, SP (1986). [4] H.C. M. Lengler, Caracterização de um fonolito ocorrente no Rio Grande do Sul como um fundente cerâmico, Diss. Mestrado, UFRGS, Porto Alegre, RS (1998).

[5] M. W. Carty, U. Senapati, J. Am. Ceram. Soc. 81, 1 (1998) 3-20.

[6] C. W. Sinton, Raw materials for glass and ceramics, John Wiley \& Sons, New Jersey, EUA (2006).

[7] S. R. Bragança, C. P. Bergmann, J. Eur. Ceram. Soc. 24 (2004) 2383-2388.

[8] A. Tucci, L. Esposito, E. Rastelli, C. Palmonari, E. Rambaldi, J. Eur. Ceram. Soc. 24 (2004) 83-92.

[9] T. Tarvornpanich, G. P. Souza, W. E. Lee, J. Am. Ceram. Soc. 88, 5 (2005) 1302-1308.

[10] S. M. Mussolin, C. Doneda, Int. Ceram. J. 03-04 (1997) 11-18.

[11] A. Barba, C. Feliu, J. García, F. Ginés, E. Sánchez, V. Sanz, V. Beltrán, Materias primas para la fabricación de soportes de baldosas cerámicas, $2^{\text {a }}$. Ed., ITC, Castellón (2002).

[12] G. Biffi, Il gres porcellanato, Faenza Editrice s.p.s, Faenza, Italia (1997).

[13] F. G. Llorens, Ceram. Inf. 9, 03-04 (2000).

[14] D. U. Tulyaganov, S. Agathopoulos, H. R. Fernandes, J. M. F. Ferreira, J. Eur. Cer. Soc. 26 (2006) 1131-1139.

[15] M. Oberzan, J. Holc, M. Buhb, D. Kuscer, I. Lavrac, M. Kosec J. Eur. Cer. Soc. 29 (2009) 2143-2152.

[16] J. Enrique, F. Blasco, V. Beltrán, Controles de Fabricación de Pavimentos y Revestimientos Cerámicos, Ed. AICE, Castellón, Espanha (1989).

[17] R. K. Brow, apud Lengler [4].

[18] W. M. Carty, Ceram. Eng. Sci. Proc. 23, 2 (2002) 79-94. [19] R. A. Epper, J. Am. Ceram. Soc. 46, 2 (1963) 100.

[20] L. Mattyasovszky-Zsolnay, J. Mater. Sci. 40, 9 (1957) 299-306.

[21] J. M. F. Navarro, El Vidrio, CSIC, Madrid, Espanha (1991).

[22] Y. Iqbal, P. F. Messer, W. E. Lee, J. Eur. Ceram. Soc. 21, 14 (2001) 2583-2586.

(Rec. 29/10/2009, Ac. 24/11/2009) 